\title{
Mosaic trisomy 22
}

INSERM

\section{Source}

INSERM. (1999). Orphanet: an online rare disease and orphan drug data base. Mosaic trisomy 22. ORPHA:96068

Mosaic trisomy 22 is a rare chromosomal anomaly syndrome, with a highly variable phenotype, principally characterized by prenatal and postnatal growth delay, mild to severe intellectual disability, hemiatrophy, webbed neck, ocular and cutaneous pigmentary anomalies, craniofacial dysmorphic features (e.g. microcephaly, upslanted palpebral fissures, ptosis, ear malformations, flat nasal bridge, micrognathia) and cardiac abnormalities (including ventricular and atrial septal defect, pulmonary or aortic stenosis). Hearing loss and limb malformations (e.g. cubitus valgus, syn/brachydactyly), as well as renal and genital anomalies, have also been reported. 